\title{
Assessment of the cytotoxic and mutagenic potential of dichlorvos (DDVP) using in silico classification model; a health hazard awareness in Nigeria
}

\author{
Yahaya Abdulwahid Abaukaka ${ }^{1,}$, Salihu Sanusi ${ }^{1}$, Kabir Abdullahi Ozigi ${ }^{1}$ and Fatima Umar Malo ${ }^{2}$ \\ ${ }^{1}$ Tehran University of Medical Sciences, No. 226, Qods St., Keshavarz Blvd., Tehran, Iran \\ ${ }^{2}$ Nasarawa State University, Keffi. Nigeria \\ *Correspondence: y-abaukaka@razi.tums.ac.ir
}

Received: May 06, 2020 Accepted: September 3, 2020

\begin{abstract}
Dichlorvos (DDVP) has been abused in Nigeria for suicide attempts, topical applications to treat an ectoparasitic infestation, and indiscriminate use on farm produce. Exposure to this compound in subacute concentration can cause toxicity in different tissues by alteration of the cellular antioxidative defence mechanism. This analysis is aimed at the systematic profiling of DDVP to assess its cytotoxic and mutagenic potential for human vulnerability using an in silico classification model. DDVP was grouped into categories of analogue chemical compounds generated from inventories based on structural alerts that measure the biological effects on cell lines and animal models using the quantitative structure-activity relationship (QSAR) model. The cytotoxic and mutagenic potential of DDVP was assessed by analyzing target endpoints like skin sensitization, oral/inhalation toxicity, neurotoxicity and mutagenicity. DDVP shows moderate sensitization potential that can induce skin irritation during prolonged exposure because of the presence of dichlorovenyl side-chain that interacts with cellular proteins and causes degradation. 50\% lethal dose (LD 50 ) of DDVP per body weight was determined to be $26.2 \mathrm{mg} / \mathrm{kg}$ in a rat model at $95 \%$ confidence range for acute oral toxicity, and $14.4 \mathrm{mmol} / \mathrm{L}$ was estimated as $50 \%$ lethal concentration (LC50) in the atmosphere due to acute inhalation toxicity. DDVP can also inhibit acetylcholinesterase in the nervous system to produce nicotinic and muscarinic symptoms like nausea, vomiting, lacrimation, salivation, bradycardia, and respiratory failure may cause death. The widely used pesticide causes weak DNA methylation which can repress gene transcription on promoter sites. DDVP is volatile so it can cause oral and inhalation toxicity coupled with neurotoxicity during prolonged exposure. Serum cholinesterase blood tests should be encouraged in federal and state hospitals to investigate related health challenges as DDVP is still used in Nigeria.
\end{abstract}

Keywords: Dichlorvos, Sniper, Toxicity, Cytotoxicity, Mutagenicity, Hazard.

\section{Introduction}

Considering the diversity of organophosphate (OP) compounds, one of the most important roles includes the application in biotic activities against insect pests that are harmful to both humans and agricultural existence. OPs are classified into five groups and comprises of thirteen distinct types based on the anti-acetylcholinesterase enzyme (anti-AChE) activity derived from phosphoric and phosphinic functional groups [1]. These includes OP pesticides (OPPs) [2], nerve agents [3], OP-induced delayed polyneuropathy (OPIDP) [4], OP-induced intermediate syndrome (OPIMS) [5], and OP flame retardants (OPFRs) [6]. OPs have been used in different applications ranging from agricultural to household insect control. After the restriction of organochloride pesticide in the 1970s, thirty-eight OPPs with AChE inhibitory activities were approved and registered to be used in the United States [7]. Examples of the commonly used OPPs are diazinon, dichlorvos (DDVP), methyl parathion, parathion, malathion, chlorpyrifos, phosmet, fenitrothion, tetrachlorvinphos, azamethiphos, and azinphos-methyl [8,9]. Dichlorvos is an alkenyl phosphate, also known as 2, 2-dichlorovinyl dimethyl phosphate. This compound contains phosphorus and serves as acetylcholinesterase inhibitor (AChI) by degrading acetylcholine (ACh) in AChE into choline and acetate. used as a pesticide or insecticide [10]. It is because of the phosphorylation of the hydroxymethyl group in serine residue with biologically active phosphate on the catalytic site of AChE, resulting in the accumulation of AChE and inhibition of ACh in different parts of the nervous system [11, 12]. AChE is a major cholinesterase (ChE) in living organisms, including insect pests with unique catalytic functionality. The major function of AChE is the 
termination of synaptic nerve impulses due to the hydrolyzation of the neurotransmitter and ACh. However, some insects are resistant to this catalytic activity. This manifestation led to the development of AChI as a pesticide [13, 14]. DDVP is sold in Nigeria as an agricultural formulation in a $100 \mathrm{~mL}$-size pack under the trade name "Sniper" marketed by a swiss-Nigerian chemical company. Because of its effectiveness in killing insect pests and its affordability, compared with firmly established brands of insecticide, the routine use of DDVP in many households has grown in recent times without considering the health hazards. According to the manufacturer's instructions, the chemical is said to be applied to crops in diluted formulation within a time frame, allowing it to degrade before use as food material or ingested. However, reports have shown that this product has been indiscriminately used and abused to devastating effect. According to the national agency for food and drug administration and control (NAFDAC), DDVP was registered as crop protection products (CPP) only, yet it has been misused overtime in different capacities, chief among them being the popular substance of choice in facilitating suicidal endeavours, topical application to treat ecto-parasitic infestation, and undiscerning application on food materials especially in the northern part of Nigeria.

Various agricultural and disease-transmitting household insect vectors and other invertebrate insect pests constitute two or more AChE genes (ace) that code for AChE. At the same time, mammals, birds, and fish have a single ace gene [15-17]. Common pests that possess more than one ace gene include Cimex lectularius[18] and Blattella germanica) [19]. Two ace genes have been identified in Anopheles gambiae, [20], the Anopheles pharoensis [21], Aedes aegypti [22], Culex tritaeniorhynchus [23], Culex pipiens [24], Lepeophtheirus salmonis [25], Chilo suppressalis [26] and Pardosa pseudoannulata [27]. Although insect species like fruit fly and house fly expressed a single ace gene (ace2) because of the loss of ace 1 gene [16, 24, $28]$, these insects confer a specialized resistance to insecticides resulting from the mutation where substitution changes of one or more nucleotide bases occurred through evolution [29].

Erythrocytes and nerve tissues are considered as the primary source of AChE. Erythrocytes AChE is more specific compared with liver $\mathrm{ChE}$, butyrylcholinesterase (BuChE) found in plasma [30]. Kingsley et al., reported alterations in haematology parameters of Wister rats exposed to DDVP, a marked decrease in erythrocyte counts, haematocrit, haemoglobin concentration, and iron deficiency were observed. The value returns to normal after withdrawal from the exposure, suggestive of idiopathic aplastic anaemia [31]. Another study on hematotoxicity and biochemical activities of liver enzymes indicates leucocytosis, an indicator of the immune response against the sublethal dosage of DDVP and significant elevation in liver analytes of the Sprague-Dawley rat [32]. Exposure to DDVP at a nonlethal or subacute concentration can induce toxicity in different tissues of an organism through alteration of the antioxidative defence system, as shown in the rat model [33]. Regarding the interspecies differences of erythrocytes ChE inhibition by DDVP, experimental data indicate no significant changes in the sensitivity of DDVP-induced red blood cells (RBCs) ChE inhibition in both humans and laboratory animals [34].

In the presence of $\mathrm{OP}$, aerobic organisms initiate oxidative phosphorylation in mitochondria, causing the production of reactive oxygen species (ROS), and an excess quantity results in oxidative cellular injuries [35]. Different studies validate the mechanism of $\mathrm{OP}$ pesticide and oxidative stress in relation to cellular genotoxicity and carcinogenicity. According to a study by Gupta and Ojha, they recognized the potentiality of OP by producing DNA adduct formation in peripheral lymphocytic cells of a rat model through oxidative stress initiation $[12,36]$ that causes mutation and apoptosis. It was also reported in the urinary's study, metabolites of $O P$, an association of OP exposure, and a substantial rise in DNA oxidative stress marker, 8-hydroxy-2'-deoxyguanosine (8-OHdG) which can cause cell damage [37]. It is essential to understand the nuclear-toxic effects of DDVP, causing genotoxicity, which may result in cell injury, cell death, mutagenesis, and carcinogenesis. Inhibition of $\mathrm{M}$-phase induced by an increase in micronuclei $(\mathrm{MN})$ frequency was observed in peripheral lymphocytic cells treated with DDVP. These may be because of the retention of cell cycle activities at the G0 phase, causing DNA damage and cell death [38]. To assess the genotoxicity of DDVP based on in vivo and in vitro model, it was reported, the cause of potential genotoxicity is based on the degree of DNA, RNA and protein methylation. From this indication, DDVP shows a higher binding affinity to the protein rather than DNA in an in vitro system, whereas half-life is reduced in an in vivo model because of catalytic effects that result in rapid metabolism and excretion [39]. Based on the reviewed experimental data, the likelihood of DDVP to induce mutagenesis in experimental animals remains ambiguous and conflicting [40]. This work aims at systematic profiling of DDVP to validate the cytotoxic and mutagenic potential in human exposure. Outcomes from the analysis outlined the potentiality of DDVP to induce cytotoxic and genotoxic effects through oral, inhalation, and dermal interaction

\section{Materials and Methods \\ Data grouping}

Canonical simplified molecular input line entry system (SMILES) was used to group the target chemical, DDVP (CAS number 62-73-7), into categories of the analogue compound with the aid of in-depth pragmatic background information of the chemical structure that measures the biological effects on cell lines, animal model and humans. These were performed through the use of quantitative structure-activity relationship (QSAR) model, a chemical in silico 
classification model [41] developed by the organization for economic cooperation and development (OECD), QSAR Toolbox version 4.3.1(43). It was used to categorize analogues and the studied compound based on the query profilers. Experimental results for the analogues were retrieved from QSAR inventories according to the systematic profilers. The profilers used were skin sensitization, oral toxicity, inhalation toxicity, neurotoxicity, reproductive toxicity and mutagenicity.

\section{Data-gap filling}

After data retrieval, data-gaps were filled using the toolbox library, and prospective analogues were analyzed to define the suitable endpoint of the target chemical with the application of a read-across and trend analysis module. Figure 1 illustrates the OECD QSAR flow chart from chemical input, profiling methods, databases, grouping method by category definition, data gap filling, and report generation.

\section{Result analysis}

Retrieved analogues were structured into a coherent framework based on read-across assessment framework (RAAF) [42] generated as summarized report, categorical report and data matrix. We evaluated the cytotoxic and mutagenic potential of the target chemical by analyzing the following target endpoint: skin sensitization (protein binding alerts for skin sensitization according to GSH and protein binding alerts for skin sensitization by OASIS profilers), oral and inhalation toxicity (toxic hazard classification by Cramer and organic functional groups profilers), mutagenicity (the mutagenic potential of DDVP based on DNA alerts for carcinogenicity and mutagenicity by OASIS profiler). In addition to QSAR toolbox analysis, a reliable web QSAR model, eMolTox [43] was used to predict molecular toxicity of the target molecule based on the mechanism of action on different animal models and their organs.

\section{Results}

Skin sensitization potential based on protein binding alerts for skin sensitization according to glutathione (GSH) and protein binding alerts for skin sensitization by OASIS profilers.

Protein binding alerts for skin sensitization, according to GSH is a predicted profiler for skin sensitization using the OASIS tissue metabolism simulator (TIMES) model. We profiled the target compound through 131 structural alerts, classifying chemicals into globally harmonized system of classification and labelling of chemicals (GSH) category $1 \mathrm{~B}(2 \%$; $<$ EC3 [Effective concentration including SI of 3] LLNA [local lymph node assay] $<50 \% ; 500 \mu \mathrm{g} / \mathrm{cm}^{2}<$ NOEL [no observed effect level] for HRIPT [human repeat insult patch test] $<12,500 \mu \mathrm{g} / \mathrm{cm}^{2}$ ) according to the Table 1 . The other profiler aimed to examine alerts within the target chemical responsible for interaction with skin proteins. The profiler comprises 110 structural alerts fragmented into 11 mechanistic domains, and each domain was separated into two automatic alerts.

According to the TIMES model, a molecule with this structural alert could interact with skin protein through nucleophilic substitution on thiophosphates, as described in the reaction below, classified as category 1B.

Protein binding alerts for skin sensitization by OASIS profilers categorized DDVP as a strong sensitizer based on nucleophilic substitution reaction on vinyl $\left(\mathrm{sp}^{2}\right)$ carbon atom. Chemical compounds with these alerts are capable of reacting covalently with proteins via a SNVinyl reaction at a $\mathrm{sp}^{2}$ carbon atom [44].

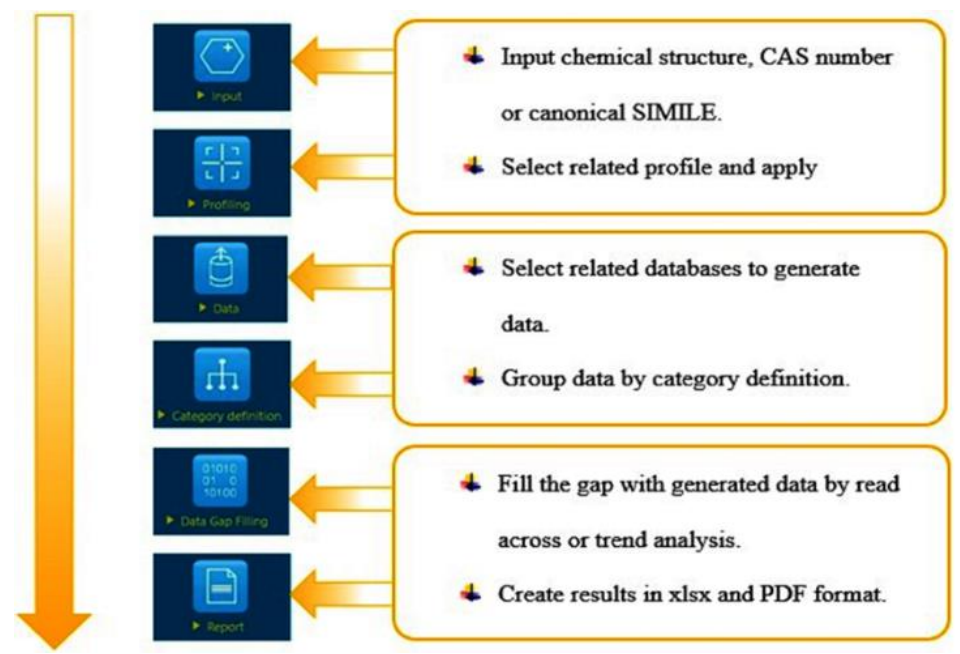

Figure 1 The organization for economic cooperation and development (OECD) quantitative structure-activity relationship model (QSAR) Toolbox mechanistic profiling flow charts indicating chemical inputs, profiling, data, category definition, data gap filling, and report. 
Table 1 Profiling results for skin sensitization based on protein binding alerts for skin sensitization according to glutathione (GSH) and protein binding alerts for skin sensitization by OASIS profilers.

\begin{tabular}{|c|c|c|c|c|c|}
\hline & Target chemical & Analogue 1 & Analogue 2 & Analogue 3 & Analogue 4 \\
\hline CAS Number & $62-73-7$ & 78-51-3 & $2921-88-2$ & $78-40-0$ & 41198-08-7 \\
\hline $\begin{array}{c}\text { Grouping } \\
\text { option }\end{array}$ & \multicolumn{5}{|c|}{$\begin{array}{l}\text { Protein binding alerts for skin sensitization according to GSH } \\
\text { Protein binding alerts for skin sensitization by OASIS }\end{array}$} \\
\hline Targets & \multicolumn{5}{|c|}{$\begin{array}{l}\text { Skin sensitization Category } 1 \mathrm{~B} \text {, (thio) phosphates. } \\
\mathrm{S}_{\mathrm{N} 2} \text { nucleophilic substitution at } \mathrm{sp}^{3} \text { carbon atom, (thio)phosphates } \\
\text { t a vinylic }\left(\mathrm{sp}^{2}\right) \text { carbon atom, vinyl type compounds with electron-withdrawing groups }\end{array}$} \\
\hline \multicolumn{2}{|c|}{ Predicted value } & \multicolumn{2}{|c|}{ Confidence range } & \multicolumn{2}{|c|}{ p-value } \\
\hline \multicolumn{2}{|c|}{ Positive } & \multicolumn{2}{|c|}{$80.0 \%$} & \multicolumn{2}{|c|}{0.188} \\
\hline
\end{tabular}

Oral and inhalation toxicity estimation based on organic functional groups, toxic hazard classification by Cramer (extended) profilers, and dichlorvos (DDVP) toxicity and mechanism of action estimated by the eMolTox quantitative structure-activity relationship (QSAR) model

We assessed oral and inhalation toxicity based on organic functional group and toxic hazard classification by Cramer profiler (extension). This compiled target chemical into different levels of toxicological concern by original Cramer's rule which includes, possibly harmful OP or organophosphothionate and toxic classes (Low [Class I], intermediate [Class II], high [Class III]) in Table 2. eMolTox estimated potential toxicity and mechanism of action on different animal models based on structural alerts associated with the specific toxic endpoint.

\section{Mutagenic potential of dichlorvos (DDVP) based on DNA alerts for carcinogenicity and mutagenicity by OASIS Profiler}

The target molecule was defined based on DNA alerts for carcinogenicity and mutagenicity by OASIS profiler for genetic toxicity and carcinogenicity. The profiler incorporates in vivo and in vitro gene mutation, DNA damage and repair, DNA and protein loss in the liver, chromosome aberration, and transgenic rodent mutation. The scope of this profile is to examine the occurrence of structural alerts within the target chemical compound liable for interaction with DNA related to a genetic mutation. The profiler consists of 85 structural alerts disjointed into eight mechanistic domains, and each domain alienated into mechanistic alerts $[45,46]$.

\section{Discussion}

In assessing the safety of a chemical compound, skin reaction on contact is very important, because of the health hazards. Absorption of toxic chemicals into the blood circulation can trigger allergic reaction or bodily damage which can be transient of permanent. Regarding this perspective, we assessed skin sensitization of DDVP and its potential to induce an allergic reaction after exposure. Report from the Nigerian and international news media, [47, 48] highlighted the scenario of a serving youth corp who died from the toxic effect of the DDVP after using it to treat human head louse (Pediculus humanus capitis) infestation. Safety of a chemical compound significantly depends on the proportion of the skin absorption and gradation of percutaneous or dermal absorption. This reflects the plausibility of systematic lethal effects, like an immune-mediated allergic response. Therefore, DDVP has shown a maximum dermal absorption in an in vitro human skin model $[49,50]$. Based on the mechanistic analysis of skin sensitization potential, table 1 shows the results as categorized by skin sensitization profiler. The structural alerts were primarily based on bioanalysis (LLNA assay) of chlorpyrifos described by Aptula et al., [51], Pyne, and Walsh [52] according to the QSAR Toolbox. The positive prediction
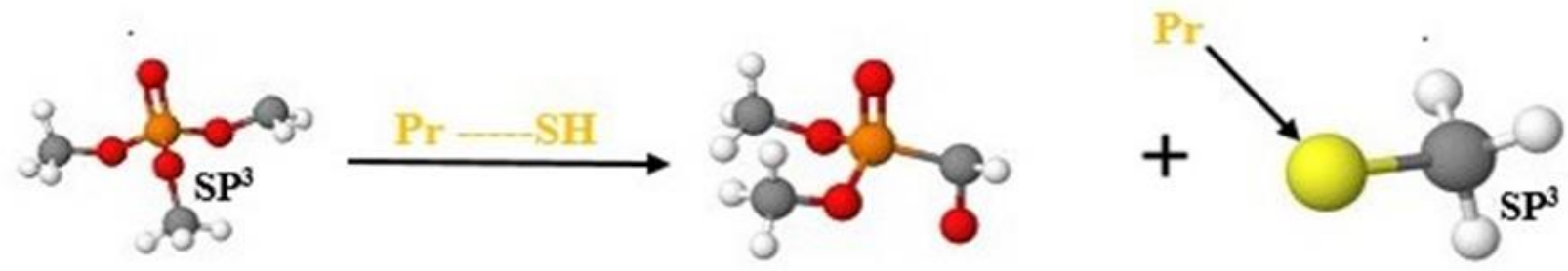

Figure 2 Structure of the $\mathrm{S}_{\mathrm{N}} 2$ reaction mechanism where alkyl groups bonded to leaving groups such as -OPO $\left(\mathrm{OCH}_{3}\right)_{2}$ in the presence of glutathione $(\mathrm{GSH})$ protein and deplete it by nucleophilic substitution at a $\mathrm{sp}^{3}$ carbon atom to initiate sensitization. 
Table 2 Acute oral and inhalation toxicity profiled by organic functional groups.

\begin{tabular}{ccc}
\hline Grouping option & Toxic hazard classification by Cramer (extension) & Organic functional groups \\
\hline Target & High toxic (Class III) & Phosphate ester and Alkenyl halide \\
\hline & Predicted value & Confidence range \\
\hline $26.2 \mathrm{mg} / \mathrm{kg} / \mathrm{bw}$ & $95.0 \%$ \\
Predicted endpoint (OECD Principle 1 - Defined endpoint): Human Health Hazards; Acute Toxicity; LD $50 ;$ Oral; Rat; $24 \mathrm{~h}$ \\
\hline 14.4 mmol/L/atm & $95.0 \%$ \\
Predicted endpoint (OECD Principle 1 - Defined endpoint): Human Health Hazards; Acute Toxicity; LC50; Inhalation; Mouse; 15 min \\
\hline
\end{tabular}

of DDVP indicates sensitization potential based on GSH categorization (category 1, a substance classified as sensitizer) and sub-categorization (sub-category B with low-to-moderate potency in an animal, supposed to have sensitization potential in human) with LLNA EC3 value $>2 \%[53,54]$. The other profiler, protein binding alerts for skin sensitization by OASIS categorized DDVP as a strong sensitizer centred on nucleophilic substitution reaction with protein at vinyl $\left(\mathrm{sp}^{2}\right)$ carbon atom, as shown in Figure 3. However, this profiler was limited due to lack of analogues from the OECD data library. However, the result was based on the prediction of the mechanistic alert of the target molecule. From the results of Table 1 , we observed DDVP as a potential moderate sensitizer that can induce skin inflammation on prolonged exposure, at higher dosages and concentration.

We defined adverse effects of DDVP based on the estimation of severity posed on endpoint upon exposure to the body. The predicted parameters comprise acute oral toxicity, inhalation toxicity, and previously mentioned, skin sensitization. Oral and inhalation toxicity in Table 2 were profiled by organic functional groups categorized as a phosphate ester/alkenyl halide and toxic hazard classification by Cramer extension. They are class III molecule that described as potentially toxic and carcinogenic inducer through cytochrome P450 and GSH transferase [55, 56]. From systematic profiling of target molecule and analogues, $26.2 \mathrm{mg} / \mathrm{kg} /$ body weight of DDVP was estimated as $50 \%$ lethal dose (LD50) in a rat model at $95 \%$ confidence range for acute oral toxicity. This result was compared to an in vivo study of $50 \%$ acute oral lethal dosage on a fed experimental animal with DDVP which are 25 to $80 \mathrm{mg} / \mathrm{kg}$ in rats, 100 to $1090 \mathrm{mg} / \mathrm{kg}$ in dogs, $15 \mathrm{mg} / \mathrm{kg}$ in chickens, 11 to $12.5 \mathrm{mg} / \mathrm{kg}$ in rabbits, and 61 to $175 \mathrm{mg} / \mathrm{kg}$ in mice [57-59]. Another typical route of exposure to DDVP that pose a threat to human health is inhalation as vapour or gases (irritating gases like phosphorous and chlorine dioxide) due to the volatile nature. $14.4 \mathrm{mmol} / \mathrm{L}$ ATM was estimated as LC 50 for acute inhalation toxicity in a mouse model within a 15-minute time frame. These indicate high toxicity through inhalation on continuous or repetitive exposure of low quantities and can cause toxic respiratory effects. The toxicological effects were also observed in different parts of the physiological organs of experimented animals in Table 3, based on similar positive molecules. The example of injuries caused by DDVP incorporates an agonist of the antioxidant response element (ARE) signalling pathway in the liver; blocker of OATP1B1 transporter in the liver, an antagonist of the peroxisome proliferator-activated receptor-gamma (PPARg) signalling pathway in kidney, heart, and immune system; and modulator of AChE in central nerve system (CNS). On neurotoxic effects, DDVP causes an elevated level of ACh that activates the nicotinic and muscarinic symptoms of the CNS and peripheral nerve system (PNS). For example, nausea, vomiting, lacrimation, salivation, bradycardia, and respiratory failure may cause death [60]. According to Illés and László, subchronic administration of DDVP $(0.8 \mathrm{mg} / \mathrm{kg}$ daily for six weeks) significantly altered the function of CNS in CFY male rats [61].

The mutagenicity was profiled by grouping and subcategorization of structural alerts that centred on target mechanistic reaction ( $\mathrm{S}_{\mathrm{N}}$, alkylation, alkyl-phosphates, alkyl-thiophosphates and alkyl-phosphonates) in Table 4 and Table 5. Through arbitrary profiling by data filling, the target chemical was read across analogues with similar structural alerts to evaluate the qualitative endpoint of the compound. Report generated for the in vitro profiling predicts Salmonella typhimurium strain TA100 and T98 to be negative based on the value of reading analogues with S9 rat liver metabolizing
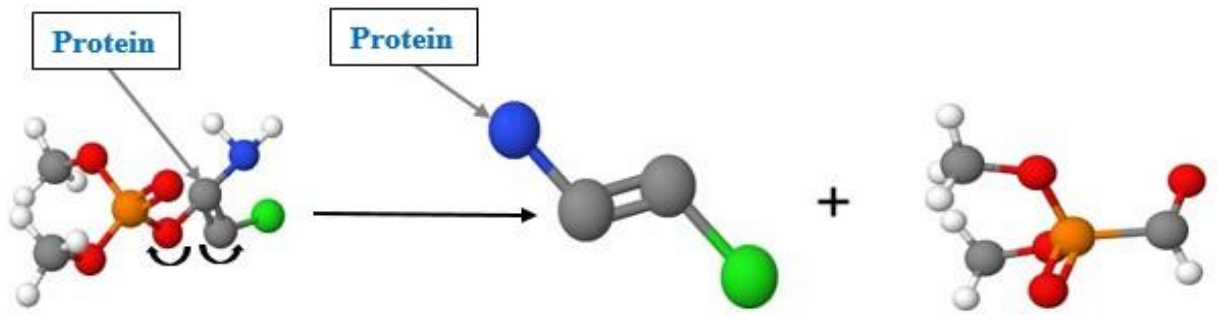

Figure 3 Structure of $\mathrm{S}_{\mathrm{N}} \mathrm{Vinyl}$ nucleophilic substitution reaction of vinylic $\left(\mathrm{sp}^{2}\right)$ carbon atom. This mechanistic reaction is responsible for the ability of this class of chemical to react with proteins. 
Table 3 Dichlorvos (DDVP) toxicity and mechanism of action estimated by eMolTox model.

\begin{tabular}{|c|c|c|c|}
\hline Mode of action & Injury & Confidence & 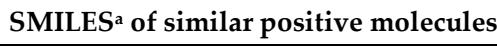 \\
\hline Acute oral toxicity $\left(\mathrm{LD}_{50}<50 \mathrm{mg} / \mathrm{kg}\right.$ ) & Rat & 0.95 & $\mathrm{COP}(=\mathrm{O})(\mathrm{OC}) \mathrm{OC}=\mathrm{C}(\mathrm{Cl}) \mathrm{Cl}$ \\
\hline $\begin{array}{l}\text { Agonist of the antioxidant response element (ARE) } \\
\text { signaling pathway }\end{array}$ & Liver & 0.93 & $\mathrm{COP}(=\mathrm{O})(\mathrm{OC}) \mathrm{OC}=\mathrm{C}(\mathrm{Cl}) \mathrm{Cl}$ \\
\hline Acute oral toxicity $\left(\mathrm{LD}_{50}<300 \mathrm{mg} / \mathrm{kg}\right.$ ) & Rat & 0.95 & $\mathrm{COP}(=\mathrm{O})(\mathrm{OC}) \mathrm{OC}=\mathrm{C}(\mathrm{Cl}) \mathrm{Cl}$ \\
\hline Block OATP1B1 transporter & Liver & 1 & $\mathrm{COP}(=\mathrm{O})(\mathrm{OC}) \mathrm{OC}(\mathrm{Br}) \mathrm{C}(\mathrm{Cl})(\mathrm{Cl}) \mathrm{Br}$ \\
\hline $\begin{array}{l}\text { An antagonist of the peroxisome proliferator-activated } \\
\text { receptor-gamma (PPARg) signaling pathway }\end{array}$ & $\begin{array}{l}\text { Kidney, Heart, } \\
\text { immune }\end{array}$ & 0.91 & $\mathrm{COP}(=\mathrm{O})(\mathrm{OC}) \mathrm{OC}=\mathrm{C}(\mathrm{Cl}) \mathrm{Cl}$ \\
\hline Modulator of acetylcholinesterase (AChE) & $\begin{array}{l}\text { Central nervous } \\
\text { system }\end{array}$ & 0.98 & $\mathrm{COP}(=\mathrm{O})(\mathrm{OC}) \mathrm{OC}=\mathrm{C}(\mathrm{Cl}) \mathrm{Cl}$ \\
\hline Acute oral toxicity $\left(\mathrm{LD}_{50}<50 \mathrm{mg} / \mathrm{kg}\right.$ ) & Mouse & 0.982 & $\mathrm{CCOP}(=\mathrm{O})(\mathrm{OC}) \mathrm{OC}=\mathrm{C}(\mathrm{Cl}) \mathrm{Cl}$ \\
\hline Acute oral toxicity $\left(\mathrm{LD}_{50}<300 \mathrm{mg} / \mathrm{kg}\right.$ ) & Rabbit & 1 & $\mathrm{COP}(=\mathrm{O})(\mathrm{OC}) \mathrm{OC}=\mathrm{C}(\mathrm{Cl}) \mathrm{Cl}$ \\
\hline Acute oral toxicity $\left(\mathrm{LD}_{50}<300 \mathrm{mg} / \mathrm{kg}\right)$ & Mouse & 0.994 & $\mathrm{COP}(=\mathrm{O})(\mathrm{OC}) \mathrm{OC}=\mathrm{C}(\mathrm{Cl}) \mathrm{Cl}$ \\
\hline
\end{tabular}

a SMILES = simplified molecular input line entry system

simulator, though, the observed value of T100 was positive which is similar to the finding of Braun et al., [62]. Another predicted negative result was the assay on Chinese hamster ovary cell line with a p-value of 0.227 . The positive value was predicted in a mouse cell line, lymphoma L5178Y cells and Chines hamster lung cell, but statistically insignificant. Table 5 shows the profile of DDVP mutagenicity in different models of the mouse, the CD1, ICR, NMRI and swiss mouse. All the in vivo predictions were negative, as it was confirmed with the review of Boot et al., [39]. There have been no significant findings that DDVP is genotoxic in an in vivo model that is relevant to human exposure based on the evaluation of the results from this study and previous findings. More also, an expert review by the European Food Safety Authority (EFSA) described DDVP as an in vitro mutagen with limited potential to induce mutagenicity in an in vivo contact due to rapid metabolic degradation in an animal model [63].

Some OP fragments are recognised to assign strong electrophilicity to the conforming compounds (mainly, phosphonic and phosphoric acid derivatives). Phosphorylation and alkylation are two chemo-toxicological mechanisms recommended for the biological macromolecules. Findings show the proposed rates of alkylation by hard nucleophiles were probably combined with rates of phosphorylation and alkylation. These represent the basis of the AChI activities and neurotoxicity. The mutagenic potential of OP pesticides is characterized by the presence of the methoxyphosphinyl group

Table 4 in vitro profiling results of dichlorvos (DDVP) based on a specific endpoint conforming structural alert, mechanistic alerts and domain.

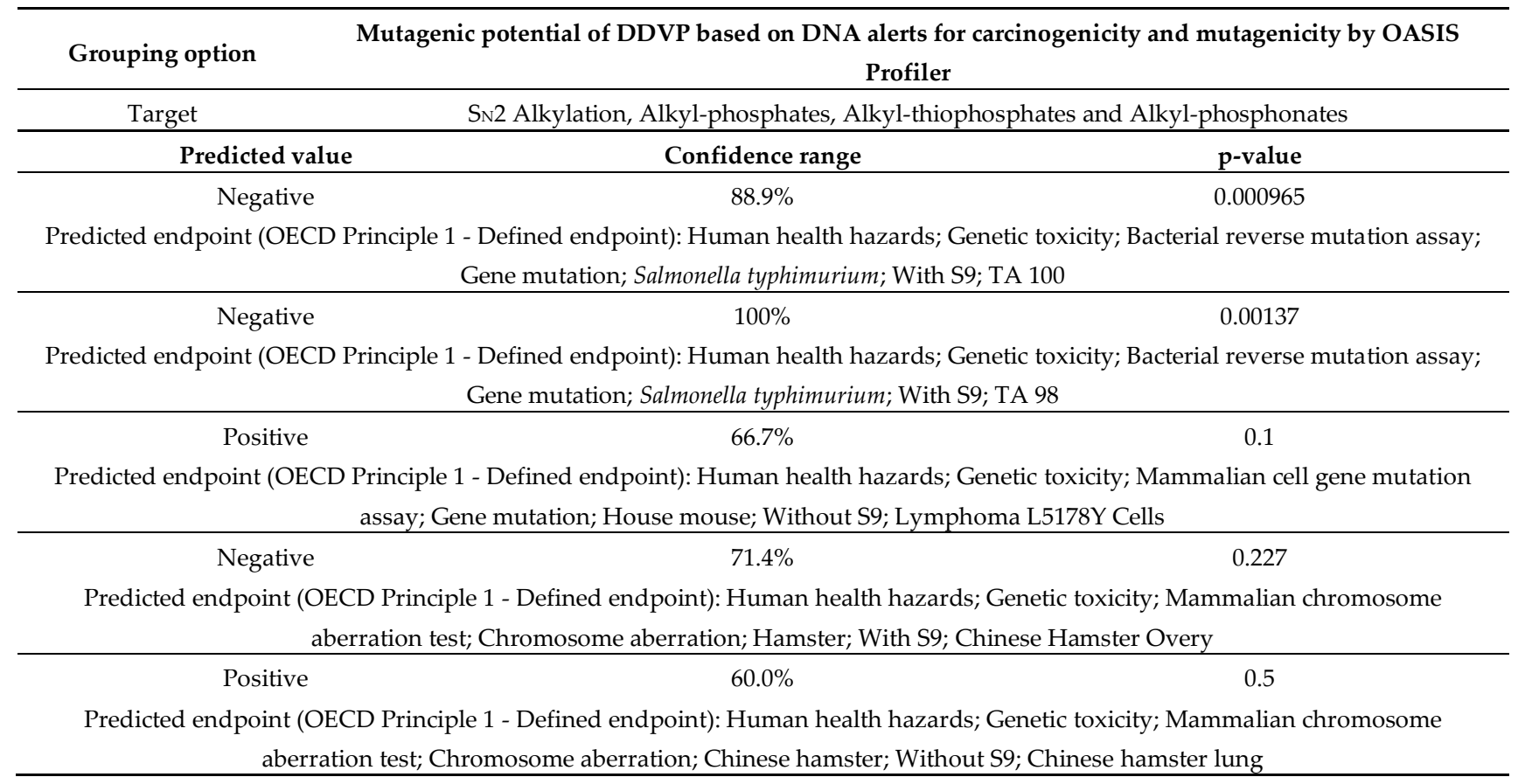


Table 5 in vivo profiling results of dichlorvos (DDVP) based on a specific endpoint conforming structural alert, mechanistic alerts, and domain

\begin{tabular}{ccc}
\hline Grouping option & Mutagenic potential of DDVP based on DNA alerts for CA and MNT by OASIS Profiler \\
\hline Target & SN2 Alkylation, Alkyl-phosphates, Alkyl-thiophosphates and Alkyl-phosphonates \\
\hline Predicted value & Confidence range & p-value \\
\hline Negative & $100 \%$ & 0.00781
\end{tabular}

Predicted endpoint (OECD Principle 1 - Defined endpoint): Human Health Hazards; Genetic Toxicity; in Vivo; Dominant Lethal Assay;

Chromosome aberration; House mouse CD1/ ICR/ NMRI.

$\begin{array}{lll}\text { Negative } & 60.9 \% & 0.202\end{array}$

Predicted endpoint (OECD Principle 1 - Defined endpoint): Human Health Hazards; Genetic Toxicity; in Vivo Mammalian Chromosome Aberration Test; Chromosome aberration; House mouse ICR/ Swiss.

Negative $\quad 100 \% \quad 3.05 \mathrm{E}-05$

Predicted endpoint (OECD Principle 1 - Defined endpoint): Human Health Hazards; Genetic Toxicity; in Vivo Micronucleus Assay; Chromosome aberration; House mouse CD-1/ NMRI/ Swiss.

in the chemical structure, which causes DNA alkylation at N7 guanine that is mutagenic as described in the Ames test of $S$. typhimurium [64]. The aromatic nitro group actively contributes to the alkylation effect of OP containing this functional group, which is absent in DDVP OP and replaced by dichlorovenyl group, as shown in Figure 4.

DDVP is considered being relatively weak methylating agent that metabolically mutagenic due to the presence of OP ester (thiophosphate group) that specifically induced strand break in an isolated DNA. Additionally, DDVP and trichlorfon, which poses similar structures, were found to be mutagenic in Salmonella strain TA1535 in an in vitro model [39, $65,66]$.

Methylation of N7 guanine fragment of DNA in an in vitro model by OPs and thiophosphates like methylbromphenvinphos, and methylparathion were based on 7-methylguanine as the main methylation adduct [67]. Overall, results from studies have confirmed that OP pesticides or insecticides such as DDVP and Naled (dimethyl 1,2dibromo-2,2-dichloroethyl phosphate) are having at least two methyl ester groups in their molecular structure induced Ames mutagenic activity [68]. Therefore, the possibility of DDVP producing alkylation mechanism is more probable but not established.
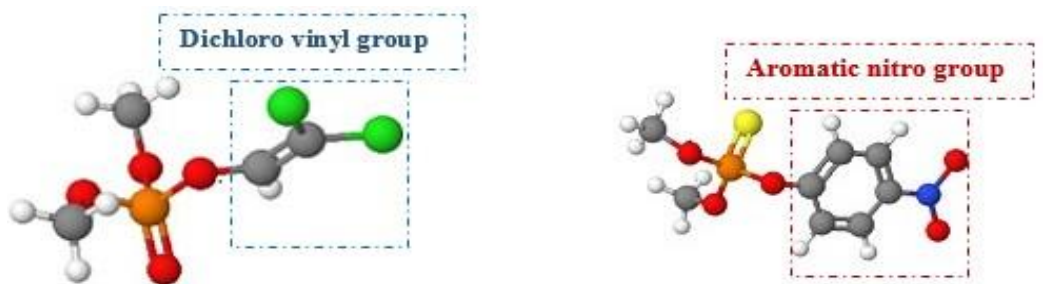

Figure 4 Structure of dichlorvos (DDVP) showing the blue box indented dichlorovinyl side chain capable of reacting covalently with proteins, but not DNA via an $\mathrm{S}_{\mathrm{N}}$ Vinyl reaction of $\mathrm{sp}^{2}$ carbon atom as described in Figure 3. The second structure shows the aromatic nitro group (methoxyphosphinyl) responsible for the strong alkylation of the organophosphate (OP) containing group.

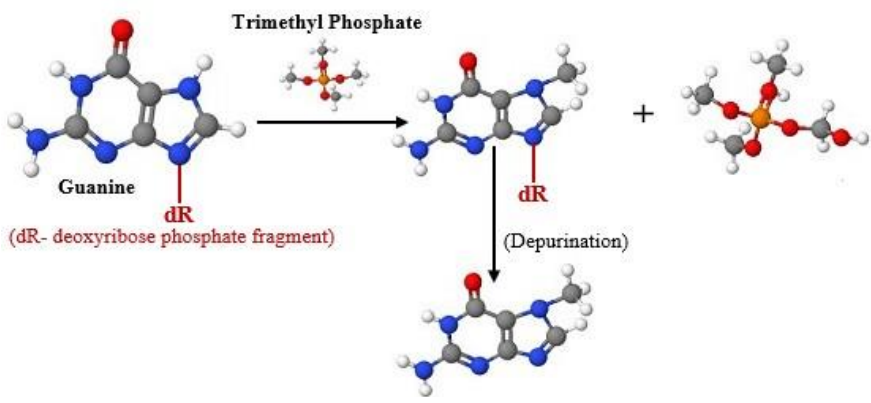

Figure 5 Methylation of DNA nucleotide (guanine) by a trimethyl phosphate group of dichlorvos (DDVP) followed by depurination of deoxyribose phosphate fragments of at N7 guanine to produce 7-methylguanine and induce strand breaks in DNA fragment. 


\section{Conclusions}

DDVP is a conceivably cytotoxic substance that can induce skin irritation after prolonged exposure because of the presence of dichlorovenyl side chain that effectively associates with cell proteins and elicits cell degradation. Acute oral and inhalation toxicity from this findings and previous examination show that OPPs have cytotoxic potential whenever they are gulped, and they can be exceptionally harmful on extended exposure which may bring about hypersensitivity of the airways and respiratory irritation. DDVP produces a genotoxic structural alert, a thiophosphate functional group (trimethyl phosphate) that is responsible for the in vitro mutagenesis. The widely used pesticide induced a weak DNA methylation that can repress gene transcription on promoter site, yet, this might not be effective in human exposure because of the rapid metabolism in an in vivo assays. It can be potentially mutagenic if higher quantity is inhaled, applied topically, and ingested through food as it has been used to preserve farm products. We suggest a routine cholinesterase blood serum test should be introduced in federal and state hospitals to investigate related health challenges as DDVP is still used in Nigeria.

\section{Acknowledgement}

We thank Mr Suleiman Bello Yahaya, the deputy director of the national population commission (NPC), Abuja, Nigeria, who inspired us to conduct this research as a public sensitization on the use of dichlorvos.

\section{Conflict of interest}

The authors of this article affirm that they have no competing interests.

\section{CRediT author statement}

YAA: Conceptualization, Methodology, Software, Writing-Original draft; SS: Writing-Reviewing and Editing; KAO: Writing-Reviewing and Editing; FUM: Writing-Reviewing and Editing

\section{References}

[1] Gupta RC. Classification and uses of organophosphates and carbamates. Toxicology of Organophosphate \& Carbamate Compounds: Academic Press; 2006. 5-24.

[2] Munoz-Quezada MT, Lucero B, Iglesias V, Levy K, Munoz MP, Achu E, et al. Exposure to organophosphate (OP) pesticides and health conditions in agricultural and non-agricultural workers from Maule, Chile. Int J Environ Health Res 2017;27(1):82-93.

[3] Sidell FR, Newmark J, McDonough JH. Nerve agents. Med Asp Chem Warfare 2008:155-219.

[4] Lotti M, Moretto A. Organophosphate-induced delayed polyneuropathy. Toxicol Rev 2005;24(1):37-49.

[5] Karalliedde L, Baker D, Marrs TC. Organophosphate-induced intermediate syndrome: aetiology and relationships with myopathy. Toxicol Rev 2006;25(1):1-14.

[6] Pantelaki I, Voutsa D. Organophosphate flame retardants (OPFRs): A review on analytical methods and occurrence in wastewater and aquatic environment. Sci Total Environ 2019;649:247-263.

[7] Pope CN. Organophosphorus pesticides: do they all have the same mechanism of toxicity? J Toxicol Environ Health Part B, Crit Rev 1999;2(2):161-181.

[8] Georgiadis N, Tsarouhas K, Tsitsimpikou C, Vardavas A, Rezaee R, Germanakis I, et al. Pesticides and cardiotoxicity. Where do we stand? Toxicol Appl Pharmacol 2018;353:1-14.

[9] Sidhu GK, Singh S, Kumar V, Dhanjal DS, Datta S, Singh J. Toxicity, monitoring and biodegradation of organophosphate pesticides: A review. Crit Rev Environ Sci Technol 2019;49(13):1135-1187.

[10] Agarwal S, Chaudhary B, Bist R. Protective propensity of bacoside A and bromelain on renal cholinesterases, gammaAminobutyric acid and serotonin level of Mus musculus intoxicated with dichlorvos. Chem-Biol Interact 2017;261:139-144.

[11] Vale A, Lotti M. Organophosphorus and carbamate insecticide poisoning. Handb Clin Neurol 2015;131:149-168. 
[12] Ojha A, Gupta YK. Study of commonly used organophosphate pesticides that induced oxidative stress and apoptosis in peripheral blood lymphocytes of rats. Hum Exp Toxicol 2017;36(11):1158-1168.

[13] Fournier D, Bride JM, Hoffmann F, Karch F. Acetylcholinesterase. Two types of modifications confer resistance to insecticide. J Biol Chem 1992;267(20):14270-14274.

[14] Silman I, Sussman JL. Acetylcholinesterase: how is structure related to function? Chem-Biol Interact 2008;175(1-3):310.

[15] Polsinelli GA, Singh SK, Mishra RK, Suranyi R, Ragsdale DW, Pang YP, et al. Insect-specific irreversible inhibitors of acetylcholinesterase in pests including the bed bug, the eastern yellowjacket, German and American cockroaches, and the confused flour beetle. Chem-Biol Interact 2010;187(1-3):142-147.

[16] Ye X, Yang L, Stanley D, Li F, Fang Q. Two Bombyx mori acetylcholinesterase genes influence motor control and development in different ways. Sci Rep 2017;7(1):1-9.

[17] Kim YH, Lee SH. Invertebrate acetylcholinesterases: insights into their evolution and non-classical functions. J AsiaPacific Entomol 2018;21(1):186-195.

[18] Seong KM, Kim YH, Kwon DH, Lee SH. Identification and characterization of three cholinesterases from the common bed bug, Cimex lectularius. Insect Mol Biol 2012;21(2):149-159.

[19] Kim JI, Jung CS, Koh YH, Lee SH. Molecular, biochemical and histochemical characterization of two acetylcholinesterase cDNAs from the German cockroach Blattella germanica. Insect Mol Biol 2006;15(4):513-522.

[20] Weill M, Fort P, Berthomieu A, Dubois MP, Pasteur N, Raymond M. A novel acetylcholinesterase gene in mosquitoes codes for the insecticide target and is non-homologous to the ace gene in Drosophila. Proc Biol Sci 2002;269(1504):2007-2016.

[21] Wassim NM. Isolation of acetylcholinesterase gene from Egyptian Anopheles pharoensis (Theobald). J Basic Appl Zool 2012;65(1):79-82.

[22] Mori A, Lobo NF, deBruyn B, Severson DW. Molecular cloning and characterization of the complete acetylcholinesterase gene (Ace1) from the mosquito Aedes aegypti with implications for comparative genome analysis. Insect Biochem Mol Biol 2007;37(7):667-674.

[23] Nabeshima T, Mori A, Kozaki T, Iwata Y, Hidoh O, Harada S, et al. An amino acid substitution attributable to insecticide-insensitivity of acetylcholinesterase in a Japanese encephalitis vector mosquito, Culex tritaeniorhynchus. Biochem Biophys Res Commun 2004;313(3):794-801.

[24] Huchard E, Martinez M, Alout H, Douzery EJ, Lutfalla G, Berthomieu A, et al. Acetylcholinesterase genes within the Diptera: takeover and loss in true flies. Proc Biol Sci 2006;273(1601):2595-2604.

[25] Kaur K, Bakke MJ, Nilsen F, Horsberg TE. Identification and Molecular Characterization of Two Acetylcholinesterases from the Salmon Louse, Lepeophtheirus salmonis. PloS one. 2015;10(5):e0125362.

[26] Hui XM, Yang LW, He GL, Yang QP, Han ZJ, Li F. RNA interference of ace1 and ace2 in Chilo suppressalis reveals their different contributions to motor ability and larval growth. Insect Mol Biol 2011;20(4):507-518.

[27] Meng X, Li C, Xiu C, Zhang J, Li J, Huang L, et al. Identification and biochemical properties of two new acetylcholinesterases in the pond wolf spider (Pardosa pseudoannulata). PloS one. 2016;11(6):e0158011.

[28] Jiang XC, Jiang XY, Liu S. Molecular characterization and expression analysis of two acetylcholinesterase genes from the small white butterfly pieris rapae (Lepidoptera: Pieridae). J Insect Sci 2018;18(5):2.

[29] Walsh SB, Dolden TA, Moores GD, Kristensen M, Lewis T, Devonshire AL, et al. Identification and characterization of mutations in housefly (Musca domestica) acetylcholinesterase involved in insecticide resistance. Biochem $\mathrm{J}$ 2001;359(Pt 1):175-181.

[30] Mohammadi H, Jalilian J, Karimi MY, Shetab-Boushehri SV. In vitro cysteine reactivates organophosphate insecticide dichlorvos-inhibited human cholinesterases. Sultan Qaboos Univ Med K 2017;17(3):e293-e300. 
[31] Kanu KC, Ijioma SN, Atiata O. Haematological, biochemical and antioxidant changes in wistar rats exposed to dichlorvos based insecticide formulation used in southeast Nigeria. Toxics. 2016;4(4):28.

[32] Celik I, Yilmaz Z, Turkoglu V. Hematotoxic and hepatotoxic effects of dichlorvos at sublethal dosages in rats. Environ Toxicol 2009;24(2):128-132.

[33] Celik I, Suzek H. Effects of subacute exposure of dichlorvos at sublethal dosages on erythrocyte and tissue antioxidant defense systems and lipid peroxidation in rats. Ecotoxicol Environ Safety. 2009;72(3):905-908.

[34] MacGregor JA, Plunkett LM, Youngren SH, Manley A, Plunkett JB, Starr TB. Humans appear no more sensitive than laboratory animals to the inhibition of red blood cell cholinesterase by dichlorvos. Regul Toxicol Pharmacol 2005;43(2):150-167.

[35] Salim S. Oxidative stress and the central nervous system. J Pharmacol Exp Ther 2017;360(1):201-205.

[36] Chang CH, Yu CJ, Du JC, Chiou HC, Chen HC, Yang W, et al. The interactions among organophosphate pesticide exposure, oxidative stress, and genetic polymorphisms of dopamine receptor D4 increase the risk of attention deficit/hyperactivity disorder in children. Environ Res 2018;160:339-346.

[37] Lu SY, Li YX, Zhang T, Cai D, Ruan JJ, Huang MZ, et al. Effect of e-waste recycling on urinary metabolites of organophosphate flame retardants and plasticizers and their association with oxidative stress. Environ Sci Technol 2017;51(4):2427-2437.

[38] Eroglu HE. Toxic nuclear effects of the organophosphorus insecticide Dichlorvos (DDVP) in human peripheral blood lymphocytes. Acta Biologica Hungarica. 2009;60(4):409-416.

[39] Booth ED, Jones E, Elliott BM. Review of the in vitro and in vivo genotoxicity of dichlorvos. Regul Toxicol Pharmacol 2007;49(3):316-326.

[40] Authority EFS. Conclusion regarding the peer review of the pesticide risk assessment of the active substance dichlorvos. EFSA J 2006;4(6):77r.

[41] Pradeep P, Povinelli RJ, White S, Merrill SJ. An ensemble model of QSAR tools for regulatory risk assessment. J Cheminformatics 2016;8(1):48.

[42] Kuseva C, Schultz TW, Yordanova D, Tankova K, Kutsarova S, Pavlov T, et al. The implementation of RAAF in the OECD QSAR Toolbox. Regul Toxicol Pharmacol 2019;105:51-61.

[43] Ji C, Svensson F, Zoufir A, Bender A. eMolTox: prediction of molecular toxicity with confidence. Bioinformatics 2018;34(14):2508-2509.

[44] Lei MY, Xiao YJ, Liu WM, Fukamizu K, Chiba S, Ando K, et al. Nucleophilic substitution reaction at an sp2 carbon of vinyl halides with an intramolecular thiol moiety: synthesis of thio-heterocycles. Tetrahedron 2009;65(34):68886902.

[45] Mekenyan O, Dimitrov S, Serafimova R, Thompson E, Kotov S, Dimitrova N, et al. Identification of the structural requirements for mutagenicity by incorporating molecular flexibility and metabolic activation of chemicals I: TA100 model. Chem Res Toxicol 2004;17(6):753-766.

[46] Serafimova R, Todorov M, Pavlov T, Kotov S, Jacob E, Aptula A, et al. Identification of the structural requirements for mutagencitiy, by incorporating molecular flexibility and metabolic activation of chemicals. II. General Ames mutagenicity model. Chem Res Toxicol 2007;20(4):662-676.

[47] PUNCH news. ICYMI: Corps member, who washed hair with Sniper, dies 10 days to birthday 2019 [cited XX XX $X X X X]$ Available from: https://punchng.com/corps-member-who-washed-hair-with-sniper-dies-10-days-tobirthday/.

[48] BBC news Pidgin. NYSC member die afta she use 'sniper' wash hair 2019 [cited XX XX XXXX] Available from: https://www.bbc.com/pidgin/tori-48927003. 
[49] Moore CA, Wilkinson SC, Blain PG, Dunn M, Aust GA, Williams FM. Percutaneous absorption and distribution of organophosphates (chlorpyrifos and dichlorvos) following dermal exposure and decontamination scenarios using in vitro human skin model. Toxicol Let 2014;229(1):66-72.

[50] Moore CA, Wilkinson SC, Blain PG, Dunn M, Aust GA, Williams FM. Use of a human skin in vitro model to investigate the influence of 'every-day' clothing and skin surface decontamination on the percutaneous penetration of organophosphates. Toxicol Let 2014;229(1):257-264.

[51] Aptula AO, Roberts DW. Mechanistic applicability domains for nonanimal-based prediction of toxicological end points: general principles and application to reactive toxicity. Chem Res Toxicol 2006;19(8):1097-1105.

[52] Payne MP, Walsh PT. Structure-activity relationships for skin sensitization potential: development of structural alerts for use in knowledge-based toxicity prediction systems. J Chem Info Comput Sci 1994;34(1):154-161.

[53] Taylor SA, Stewardship DP. GHS. 2012.

[54] Organization for Economic Cooperation and Development (OECD). OECD Guidelines for the testing of chemicals: organization for economic; 1994.

[55] Anders MW. Glutathione-dependent bioactivation of haloalkanes and haloalkenes. Drug Meta Rev 2004;36(3-4):583594.

[56] Nevins MJ, Johnson WW. Acute toxicity of phosphate ester mixtures to invertebrates and fish. Bull Environ Contam Toxicol 1978;19(1):250-256.

[57] Handbook FC. meister publishing company. Willoughby; 1997.44094:13-47.

[58] Hayes WJ. Pesticides studied in man. 1982.

[59] Laws ER. Handbook of pesticide toxicology: Academic Press; 1990.

[60] Binukumar B, Gill K. Cellular and molecular mechanisms of dichlorvos neurotoxicity: cholinergic, nonchlolinergic, cell signaling, gene expression and therapeutic aspects. 2010.

[61] Dési I, Nagymajtényi L. Neurotoxicologic investigations of the pesticide dichlorvos (DDVP). Effects on the central and peripheral nervous system. Toxicol 1988;49(1):141-148.

[62] Braun R, Schoneich J, Weissflog L, Dedek W. Activity of organophosphorus insecticides in bacterial tests for mutagenicity and DNA repair--direct alkylation vs. metabolic activation and breakdown. I. Butonate, vinylbutonate, trichlorfon, dichlorvos, demethyl dichlorvos and demethyl vinylbutonate. Chem-Biol Interact 1982;39(3):339-350.

[63] European Food Safety Authority (EFSA). Conclusion on the peer review of the pesticide risk assessment of the active substance dichlorvos. EFSA Sci Rep 2006;77:1-43.

[64] Wang T, Lin C-M, Lo L-W. Genotoxicity of methoxyphosphinyl insecticide in mammalian cells. Zool Stud 2003;42(3):462-469.

[65] Löfroth G. Alkylation of DNA by dichlorvos. Naturwissenschaften. 1970;57(8):393-394.

[66] Carere A, Ortali V, Cardamone G, Morpurgo G. Mutagenicity of dichlorvos and other structurally related pesticides in Salmonella and Streptomyces. Chem-Biol Interact 1978;22(2-3):297-308.

[67] Wiaderkiewicz R, Walter Z, Reimschussel W. Sites of methylation of DNA bases by the action of organophosphorus insecticides in vitro. Acta Biochimica Polonica. 1986;33(2):73-85.

[68] Hour TC, Chen L, Lin JK. Comparative investigation on the mutagenicities of organophosphate, phthalimide, pyrethroid and carbamate insecticides by the Ames and lactam tests. Mutagenesis. 1998;13(2):157-166. 